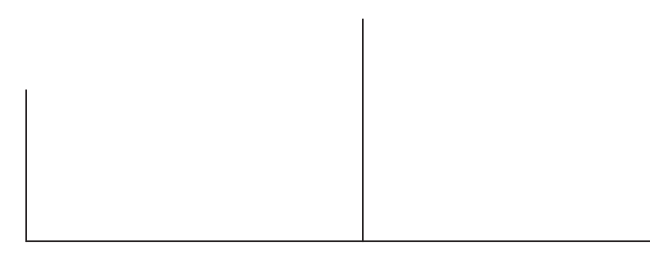

Rev. Latinoam. Psicopat. Fund., III, 4, 92-111

\title{
Psicoterapia e empirismo
}

\author{
Durval Mazzei Nogueira Filho
}

\begin{abstract}
O autor discute as possíveis implicações para o exercício da psicanálise o contexto que obriga que a eficiência dos procedimentos terapêuticos seja apurada pelo método empírico. Alerta que a facilidade de se criticar esta metodologia, a partir de outras posições filosóficas e éticas, não deve servir como argumento para a comunidade psicanalítica receber com desdém as críticas que surgem.
\end{abstract}

Palavras-chave: Psicoterapia, empirismo, pesquisa 


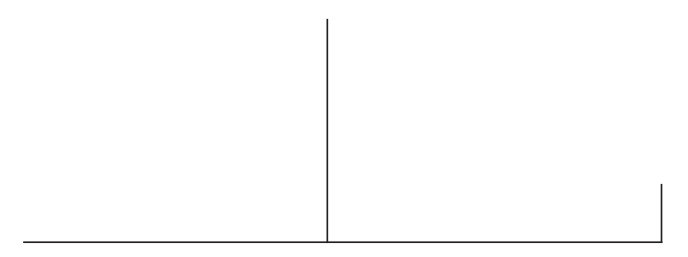

\section{Introdução}

Este é um texto de um psicanalista. Este texto entende que a psicanálise, apesar de ter nascido como uma forma mais eficiente de tratamento das neuroses, em sua teoria e em sua prática não se instrumentaliza apenas como um tratamento do espírito, uma psicoterapia. Menos ainda se o termo "psicoterapia" e sua derivação vulgarizada - terapia - tomar o sentido de passar um tempo agradável na presença de alguém ou no desempenho de alguma atividade social ou recreacional. Se um sujeito busca o psicanalista com esta intenção, certamente dará com os burros n’água. A psicanálise é um procedimento que propõe-se a tratar o espírito, mas não pela via simplificada e ingênua de instaurar com pressa e açodamento o bemestar.

Não obstante, em virtude da fúria regulamentadora - de inspiração no sistema jurídico norte-americano - oriunda do crescente economicismo nos serviços de saúde (Frankford, 1994), as diferenças entre as várias modalidades de tratamento psíquico são obscurecidas em função da obrigatória simplificação que a regulamentação exige. Assim sendo, diante deste discurso, a especificidade da abordagem psicanalítica não é levada em consideração e, neste texto, será definida como psicoterapia. É a denominação que entendem os interlocutores imaginários deste escrito. Este fator extradebates científicos tem exercido o papel de uma admoestação 


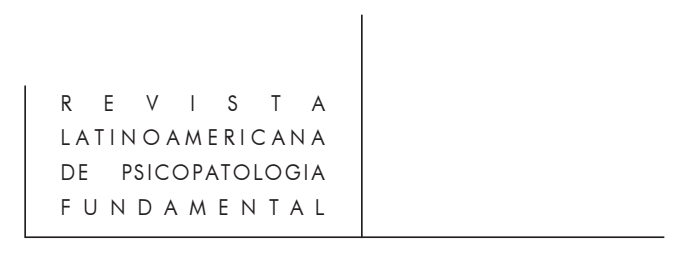

externa, pondo em relevo o que há de pior na competição e na rivalidade entre os pesquisadores: o interesse que se depreende das pesquisas está limitado a demonstrar ao empresário de plantão que sou mais eficiente e mais científico que o outro.

O pano de fundo a este cenário é a presença clara da influência dos inumeráveis fármacos à disposição do mercado, indicados para o tratamento das mesmas condições que as psicoterapias se propõem. A psicanálise deve, no mínimo, participar deste debate. Caminhando sobre uma faca cortante, na medida em que ganha ao usar as mesmas regras de conduta e na medida em que pode perder a sua especificidade. É um risco...

\section{A respeitabilidade das psicoterapias em foco}

Desde o seu aparecimento, a psicoterapia recebeu o selo de uma prática exótica, tendo em vista que se alinhou entre as medidas terapêuticas à disposição do aparelho médico. Esta condição não foi desatendida por seus pioneiros. Freud (1973) e Binswanger (1973) preocuparam-se, em palestras dirigidas a platéias médicas, em fundamentar seus princípios lógicos e desmontar o parentesco que esta atividade teria com as práticas mágicas. Afinal de contas, o meio pelo qual as psicoterapias exercem a sua eficácia é a palavra e não pressupõe nenhuma ação de outra natureza sobre o sujeito que a elas se submete. Não é mais que esta característica a semelhança possível entre uma atividade puramente racional, como são as psicoterapias, e qualquer outra prática de ação à distância ou de purgação confessional que possa qualificar as atividades mágicas. Na verdade, aventar esta semelhança repousa em um absoluto desconhecimento da teoria e do pragmatismo de qualquer sistema psicoterapêutico. Pois a psicoterapia nem em aparência pode ser assimilada à magia. Eficácia simbólica é outra coisa. A diferença precípua sobre os outros procedimentos terapêuticos é o privilégio da escuta sobre o olhar. $\mathrm{E}$ este privilégio é absolutamente irredutível. A psicoterapia para todo o sempre é uma atividade de linguagem, escuta e participação e não se resume à exposição visual e imagética, marcadas pela passividade, ao saber douto do terapeuta.

Não resta dúvida que a psicoterapia, em um período histórico, angariou simpatias. Nunca de maneira onipresente. Este mesmo período histórico foi marcado pelo desenvolvimento de práticas terapêuticas bem ao gosto do olhar. Desde a convulsoterapia e psicocirurgias até a psicofarmacologia. Este fato é claro para aqueles que não fingem ignorar a história e não a obscurecem afirmando que a psicoterapia teve toda a respeitabilidade reconhecida entre as décadas de 1920 e 1970. Que este período foi, efetivamente, um período de intensas e radicais mudanças na música, nas artes plásticas e visuais, nos costumes e - em mão oposta - de desenvolvimento da cultura de massas é evidente. A cultura de massas é dita em 


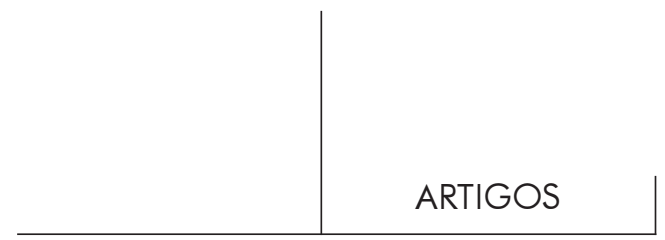

"mão oposta" em função de banalizar qualquer produção, transformando-a em um objeto de consumo imediato, prático e pouco aberto a singularidades. Que a principal corrente psicoterapêutica, ao demonstrar que havia uma gramática, uma lógica e, portanto, uma racionalidade em manifestações tão díspares quanto um sintoma neurótico, um sonho e um lapso de linguagem influenciou poetas e artistas a ponto de colaborar para a constituição do surrealismo, como relatam os historiadores da arte é um saber comum (Argan, 1996). O que poucos gostam de discutir é o caminho inverso. A influência que a cultura de massas, travestida de ciência, trouxe para o debate atual entre o privilégio psicoterapêutico à escuta e a sempre presente suspeita que a psicoterapia é tão embusteira e ignorante quanto o xamã da última tribo amazônica. Assim, o traço imediatista e prático presente na cultura de massas é um dos fatores que concorrem para que atividade psicoterapêutica passe a exibir, também, a marca da rapidez. A ponto de estar presente em uma série de publicações, das mais variadas origens e objetivos, que as psicoterapias devem ser breves, didáticas e focais.

Este é um dos pilares que sustenta a versão atual que questiona a respeitabilidade da psicoterapia. Qualquer procedimento terapêutico que possa enquadrar-se melhor na imediatez, praticidade e considerar o geral mais que o singular conta com o apoio incontinente dos pesquisadores e dos empresários da saúde - públicos ou privados - que se debruçarão para marcá-las com o epíteto "tem sua eficiência baseada em evidências". Uma evidência construída em trabalhos empíricos que, como veremos adiante, estão pouco preocupados em perguntar se os fundamentos metodológicos são suficientes para a colheita dos resultados. Estas pesquisas são engolidas como se engolem big macs e vendidas como um incontestável produto da ciência. Não obstante a facilidade em criticar estas pesquisas, isto não autoriza que os representantes das diversas linhas de pensamento tratem esta questão com desdém. Se entre as virtudes da ciência está a retórica, a retórica que defende a superioridade do método empírico é uma das mais eficientes e críveis no contexto capitalista da gestão da saúde. Além do mais, se é certo que a atividade científica é produto de circunstâncias históricas e culturais determinadas, o espírito contemporâneo é este. Não se ouvem mais missas em latim. Mas, apesar do caráter quixotesco, nunca é suficiente lembrar que o que é apresentado maciçamente aos sentidos e ao pensamento não é necessariamente verdadeiro.

Há um outro pilar. Este é mais antigo e originado nos debates entre os próprios psicoterapeutas. É possível, de uma maneira simples, descrever o cenário no qual se dão estes esses debates como cindido em dois estilos: o cognitivo/comportamental e o psicanalítico/interpessoal (Margison \& Shapiro, 1996). Estes estilos diferem entre si em diversos pontos fundamentais. Os associados ao primeiro grupo são vaidosos da origem laboratorial e do modelo animal que utilizam e conferem, desde o início, um verniz empírico aos esquemas estruturados e breves que 


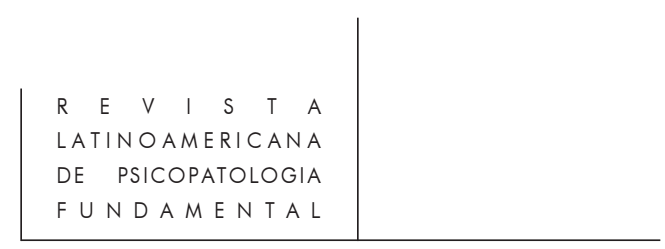

caracterizam a abordagem que fazem do sofrimento psíquico humano. São psicoterapeutas prescritores, disciplinadores, despreocupados com a investigação histórica e com a dinâmica do sintoma na subjetividade. Os associados ao segundo grupo são zelosos da relação interpessoal, não julgam útil o modelo animal, construíram os fundamentos na clínica ao escutar os sujeitos e não se preocupam com a conformação empírica das proposições. A cientificidade de seus procedimentos assemelha-se mais às ciências conjecturais. São psicoterapias investigativas que contam com a expressividade verbal dos pacientes e com a dinâmica do sintoma na história e na subjetividade. Não prescrevem e não disciplinam. Vê-se que as virtudes de um estilo coincidem justamente com a postura a não ser seguida pelo outro.

Obviamente, este cenário propicia a oportunidade de interessantes discussões entre os praticantes dos estilos. O roteiro complica-se quando uma admoestação externa exige que as psicoterapias demonstrem de maneira inequívoca para que servem, como se esta discussão já não estivesse presente nos textos de ambos os grupos. Uma interessante maneira de comentar que os psicoterapeutas não sabem o que fazem. Esta admoestação pode ser vista como uma atualização da desconfiança que acompanhou a psicoterapia desde a fundação, o período de estabelecimento e invade a atualidade. Clare (1989) representa bem esta desconfiança quando afirma que o pensamento teórico dos psicoterapeutas não se preocupa com a "evidência científica relacionada à indicação das psicoterapias ou relacionada à eficácia do processo", mas prefere basear-se nas asserções dos pacientes, decerto de pacientes bastante infantis e psicoterapeutas idem, tais como "somos pessoas e não casos", "eu peço ajuda e me dão pílulas". Efetivamente, fica difícil decidir se é má-fé ou simples ignorância do destacado autor inglês. Diante desta particular opinião, os psicoterapeutas dos dois grupos podem sentir-se desconfortáveis.

No entanto, o roteiro complica-se mais quando os admoestadores afirmam e determinam que o dispositivo à disposição dos praticantes não é outro senão o aparato empírico. Se ambos os estilos podem, irmãmente, considerar-se ofendidos por falas como a de Clare, perante esta outra proposição um grupo exulta e o outro cala-se. Dada a diferença na natureza entre os estilos concorrentes, não é lá muito difícil antecipar qual dos estilos sair-se-á melhor nas avaliações possíveis de serem aferidas pela metodologia experimental. Um estilo, o cognitivo/comportamental, originou-se no laboratório; outro estilo, o psicanalítico/interpessoal, nasceu na clínica diante dos pacientes. Não há como não concluir, aprioristicamente, que o estilo habituado a construir seus esquemas empiricamente deve obter, dada a pressa com a qual os resultados são exigidos, escores mais favoráveis. Além deste argumento prático, é notório que a comunidade psicanalítica tem uma dificuldade maior em aderir à ideologia embutida no empirismo e incluir esquemas de mensuração empíricos de tal forma que não inviabilizem o próprio procedimento. 


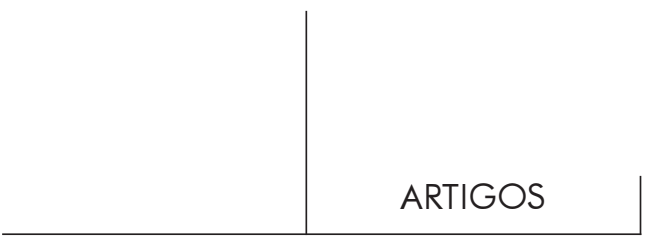

Não obstante, cabe advertir que a ojeriza que este semblante de objetividade e verdade que qualifica a metodologia empírica não deve produzir no psicanalista uma atitude olímpica contrária à conspurcação da pureza da cura psicanalítica. Apesar das dificuldades evidentes, há que buscar uma saída. O preço a pagar, como avalia Hanns (2000) pela recusa a participar "deste movimento de formalização geral das teorias e práticas (...) as abordagens psicodinâmicas correm o risco que o façam à sua revelia e as excluam legal e socialmente da atividade profissional".

E o que é alerta em Hanns, é fato em Schestatsky e Fleck (1999):

Cabe um comentário a respeito dos estudos disponíveis sobre a eficácia das psicoterapias dinâmicas... Há poucos estudos controlados e, dos que existem, poucos foram realizados por proponentes desta técnica. Usualmente a terapia psicodinâmica foi empregada como contraste a outra terapia, com as quais os autores desses estudos mais se identificavam... E é improvável que os terapeutas, nesses estudos, tenham aplicado a técnica de forma adequada, dada a falta de comprometimento com este modelo. Portanto, os achados freqüentes de que a psicoterapia psicodinâmica... tem sido menos eficaz que outras técnicas devem ser vistos com cautela, dados os problemas metodológicos assinalados, acrescentados aos prováveis vieses contrários introduzidos pelos pesquisadores.

Os autores gaúchos, na verdade, estão levantando um ponto do qual a metodologia não tem como fugir. A formação teórica do pesquisador, portanto, influi no resultado da pesquisa, apesar destas serem transmitidas como as representantes máximas da objetividade e da evidência. Parece um circo do absurdo, mas não é. A leitura de qualquer manual moderno de psiquiatria, dirigido a jovens estudantes de medicina ou de psicologia, mostra que as fobias, as obsessões e outras formas clínicas usuais no discurso psicanalítico são mais eficientemente tratadas por outras psicoterapias - notadamente, as de estilo cognitivo/comportamental - do que com a psicanálise. E ninguém se preocupa em fazer o alerta que aqui se faz. Se o timão do barco está solto, alguém pega. Para levar o barco ao porto que melhor o aprouver.

\section{Psicoterapia e ciência}

A referência que Schestatsky e Fleck fazem aos testes controlados, quando notificam que a avaliação das psicoterapias dinâmicas não foi feita por pesquisadores formados e comprometidos com o estilo, faz pensar que o dispositivo psicoterapêutico, mais do que adequar-se à metodologia empírica, apresenta questões a esse dispositivo. Precisamente: a formação do pesquisador influencia a medida. Este ponto - inegligenciável - deveria ser suficiente para deixar as comunidades interessadas nestes resultados de olhos bem abertos. No entanto, isto não tem ocor- 


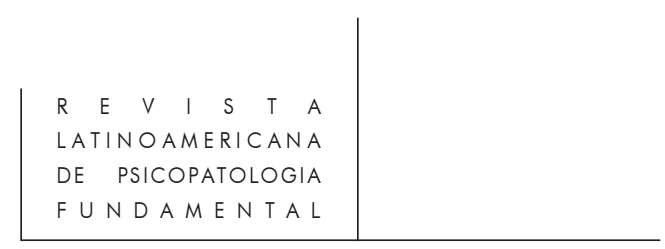

rido. Se a metodologia, mesmo com furos evidentes, foi aplicada e o trabalho publicado em algum periódico de certa representabilidade emoldurado por estatísticas e gráficos, as empresas de saúde, os seguros médicos, a rede pública de saúde e mesmo associações de consumidores vão acatar que o estilo psicoterapêutico em pauta, submetido ao teste, foi sancionado pela ciência. Estes são os interlocutores imaginários. Os psicanalistas não podem e não devem abandonar o barco à própria sorte, mesmo que seja muito claro que não há a menor possibilidade de um obsessivo ou um fóbico realmente atravessar o fantasma com algumas sessões de psicoterapia disciplinadora e orientadora. O presente momento cultural acredita nisso e é com esta estrutura que dialogamos.

E não está proibida a criatividade. Não há nenhuma razão para encampar a pretensão positivista a uma uniforme estruturação do conhecimento científico. Não é em lugares remotos da cultura que se pode reconhecer

... que é como maneira de usar seus objetos que o pensamento científico se diferencia essencialmente de qualquer outra espécie de conhecimento. A posição característica assumida ante seus objetos não acarreta de modo algum, aliás, para o pensamento científico, a unicidade de um método, se dermos a esta palavra o sentido estrito de um conjunto de procedimentos ordenados, amplamente independentes da natureza dos objetos a conhecer (Granger, 1994).

Chalmers (1994) é mais específico ao assumir a posição que segue:

Se alguma área do conhecimento, como a psicologia freudiana ou o materialismo histórico de Marx, tivesse de receber uma crítica fundamentada no fato que não se ajusta à minha caracterização da física, isso implicaria que todo conhecimento autêntico deve adaptar-se aos métodos e aos padrões da física. Não me sinto preparado para esta proposição e penso que seria muito difícil defendê-la.

E mais adiante

... acredito que não existe nenhuma concepção atemporal e universal da ciência e do método científico que possa atender ao objetivo de avaliar todas as pretensões do conhecimento (...) Não podemos defender ou rejeitar com legitimidade pontos do conhecimento porque eles se ajustem ou não a determinados critérios já prontos de cientificidade.

O traço salientado acima - a formação psicoterapêutica do pesquisador influi na medida - obscurece a objetividade do método científico "já pronto" e isto já é reconhecido pelos mais entusiastas empiricistas do campo psicoterapêutico. Hollon (1992), um cognitivista-comportamental, contestou resultados em um estudo do NIMH (National Institute of Mental Health), alegando que, em determinado centro de pesquisa, a aplicação da psicoterapia cognitivo-comportamental foi de má qualidade. Esta possibilidade, a habilidade do psicoterapeuta em aplicar a técnica em teste, 


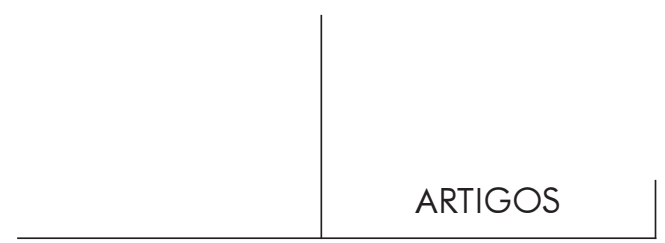

deve ser considerada um índice de que o campo psicoterapêutico, o objeto a ser medido, não se enquadra em uma metodologia restritiva. $\mathrm{O}$ curioso nesta história toda é que as correntes psicoterapêuticas de consistência teórica, lógica e prática beneficiar-se-iam desta concepção menos restritiva da metodologia científica. A rivalidade, salutar em muitos sentidos, entretanto, impede este acordo. Se as psicoterapias cognitivo-comportamentais caíram nas graças da comunidade médica, qual a razão para não aprofundar o fosso? Mas, mesmo assim, apesar deste texto não chegar a explicitar como seriam tais pesquisas, é importante que os psicanalistas, em suas sociedades, escolas e gabinetes privados, saibam que há ciência reconhecida, mesmo na ausência de unidade metodológica.

Felizmente, o andor não é tão fácil de ser sustentado. Apesar da pouca adequação da psicanálise ao empirismo, a literatura médica faz referências ao sucesso terapêutico de psicoterapias como a interpessoal (Weissmann \& Akiskal, 1984) e a Cognitiva (Tillet, 1996) e da psicoterapia psicanalítica (Clarkin, 1996) nas depressões. Apesar, então, da psicoterapia psicanalítica enquadrar-se pior no contexto experimental que a cognitiva, ela exibe um perfil de eficiência semelhante quando o trabalho é dirigido pelos próprios psicanalistas.

Um sucinto exame da metodologia empírica clássica deve esclarecer, pelo menos parcialmente, a ocorrência de resultados tão díspares. Díspar a ponto de ser possível questionar a objetividade das medidas e reconhecer um paradoxo: "o paradoxo da equivalência" (Meyer, 1996). Este paradoxo designa o fato de que, a despeito das notáveis diferenças teóricas e operativas das diversas psicoterapias, os resultados não são marcadamente diferentes. O que faz pensar que a psicanálise tem perdido a batalha e levado a marca de processo ineficiente apenas por renunciar a sustentar sua retórica em testes empíricos.

Cabe aqui uma pergunta que inclui um paradoxo: o que faz um psicanalista acreditar na autonomia dos objetos empíricos? A psicanálise está entre as disciplinas, ao lado da epistemologia e da antropologia, mais capacitadas para fazer uma crítica da tão propalada objetividade científica. E, portanto, sustentar com propriedade que este objeto - o empírico - não há além do sujeito que o formula. Freud (1895), desde o "Projeto...", todavia a sua tendência a apostar na psicanálise como parte da ciência natural, já ensinava sobre a construção dos objetos, dos objetos ordinários da realidade, os que se prestam à empiria, pelo aparelho psíquico. Um aparelho mesclado com um terreno, o terreno neuronal, disposto exclusivamente a descarregar e subvertido desta disposição pela organização que lhe confere os traços mnêmicos. Traços mnêmicos não são mais que significantes. Nada mais que linguagem, portanto. Ora, esta lógica permite formular que não há realidade consistente, realidade mensurável, sem linguagem, sem simbólico, sem cultura. E Freud não é um cavaleiro solitário nesta empreitada. Fourez (1995) diz: “... é uma visão espontânea [que] tende a acreditar que as disciplinas são determinadas por objetos 


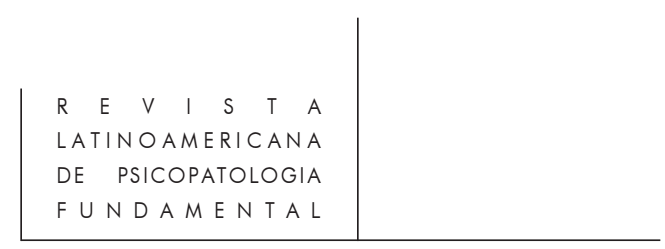

que seriam dados empiricamente". O mesmo autor instiga ao afirmar que objetos tais como "a matéria, a saúde, a Terra, o fenômeno econômico (ou psíquico, ou psicológico), a operação lógica, o território geográfico, o ambiente ecológico, o ser vivo etc." são "falsos objetos empíricos". "Nenhum destes conceitos é dado, eles são todos construídos segundo o projeto que se persegue e são socialmente aceitos". O ponto é que para os interlocutores imaginários, o objeto "socialmente aceito" atualmente, no campo das psicoterapias, é a pesquisa empírica. Mesmo que esta seja impossível. O trabalho do psicanalista, neste particular, deve ser inventar a metodologia que cabe à psicanálise e não, simplesmente, dizer "não!".

Então, uma sucinta vista de olhos no que é básico na metodologia empírica observa que os empiristas procuram isolar, no contexto das pesquisas, quais as variáveis dependentes do processo terapêutico a ser realizado. A variável dependente é aquela que certamente associa-se ao processo e não se confunde com nenhum outro elemento. No caso das psicoterapias, trata-se de saber se as ações específicas do psicoterapeuta ligam-se ao resultado pretendido. Aqui reside um impasse. Há uma dificuldade em levar a cabo o isolamento da variável dependente e separá-la da interferência das variáveis independentes que podem influenciar o processo em exame e o próprio comportamento da variável dependente. Da mesma maneira, não se isola adequadamente as variáveis nomeadas "estranhas". Estas representam a possibilidade de fatores oriundos da contra-hipótese em teste permanecerem ativas durante o correr do experimento.

Um exemplo. Dentre as diferenças entre os dois estilos psicoterapêuticos rivais, está o sentido que é dado à presença do diretor do processo. As psicoterapias cognitivo-comportamentais propõem a hipótese de que a cura de um determinado quadro clínico é uma variável dependente dos sofisticados instrumentos estruturados de orientação e ensino que usam. Enquanto as características pessoais do terapeuta, a qualidade da relação do par terapeuta/paciente não seriam determinantes do resultado do trabalho e consistiriam em elementos próprios à variável estranha ao processo em teste. Entretanto, o estilo concorrente, o psicanalítico, postula que além do que é efetivamente dito durante a cura, a vinculação pessoal do paciente ao terapeuta é que corresponde à variável dependente que favoreceria - ou não - a obediência e a adesão do paciente ao tratamento e, portanto, à produção da cura. Esta vinculação pessoal é aqui, sem precisão, nomeada transferência. A transferência, assim, corresponde à variável "estranha" ao procedimento técnico cognitivo-comportamental. Este recorte é um dos possíveis de serem construídos. E, por si só, demonstra a complexidade dos estudos que tomam a psicoterapia por objeto. O psicoterapeuta não tem como tornar-se, ao mesmo tempo, instrumento de cura e pesquisador isento. Da mesma forma, sua formação e sua habilidade pessoal não é um desígnio do estilo ao qual se dedica. Russel e Orlinsky (1996) dizem que a principal oposição à pretensão do empirismo em dar respostas definitivas so- 


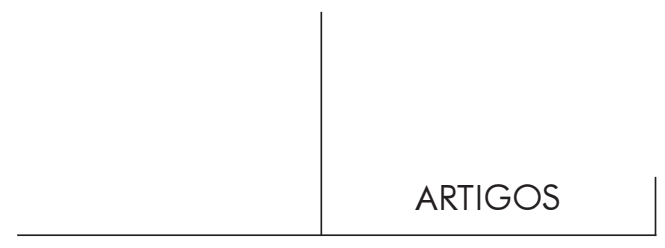

bre a eficiência do contexto psicoterapêutico acontece quando o método empírico depara-se com a estrutura formada pelo par paciente/psicoterapeuta. Se este é um argumento a favor da leitura psicanalítica, dificilmente será demonstrado pela via empírica. Convém não esquecer que os objetos empíricos não são dados passivos à disposição da acurácia dos sentidos ou da precisão dos instrumentos de medida.

Posto isto, é claro que, em nome da obediência à metodologia, o experimento capaz de avaliar qual o "componente" ativo da psicoterapia não pode confundir, de forma alguma, a hipótese com a contra-hipótese. Para que a avaliação possa ser válida e confiável, o experimento deve conter o poder lógico e pragmático de isolar o "componente ativo" do processo em teste das variáveis independentes e "estranhas". No caso particular eleito como exemplo, demonstrar que o procedimento didático e estruturado dos cognitivistas produz a cura sem a intromissão do elemento transferencial. É difícil encontrar um trabalho experimental que alcançou êxito nesta tentativa (Woody, 1983, 1995; Markowitz, 1994).

É também considerável que os testes envolvendo as psicoterapias não definiram claramente o que pode desempenhar o papel do placebo. Isto é, um nítido vazio terapêutico, um elemento sem especificidade, perante o qual a eficácia da psicoterapia estaria comparada. A comparação com placebos é uma rotina para a aprovação de medicamentos desde os grandes programas empreendidos pela administração norte-americana durante a Segunda Grande Guerra (Pignarre, 1999). Nota-se que os pesquisadores dispostos a avaliar as psicoterapias, decerto, não se preocuparam em encontrar vias distintas das empregadas para a avaliação dos medicamentos. A própria utilização do eufemismo "componente ativo da psicoterapia” já traía esta origem.

Omer e London (1989) escrevem que a exigida inespecificidade que qualifica o placebo choca-se com a possibilidade da psicoterapia agir por meios inespecíficos tais como os elementos inter-relacionais próprios ao par terapeuta/paciente em ação, assim como também seriam fatores inespecíficos a expectativa e o impacto inicial que a psicoterapia produz no paciente. Parloff (1985), considerando a diferença que pode haver entre a avaliação das psicoterapias e dos medicamentos, julga a inclusão de controles e placebos desnecessários para a mensuração dos efeitos das psicoterapias. Para Howard (1994), a pesquisa em psicoterapia apresenta mais furos práticos do que seria "suficiente para assegurar a lisura dos resultados". Assim, comenta que o processo aleatório de escolha não permite generalizações e não tem como aferir a razão pela qual o paciente aceita e persevera no tratamento. A consideração de Howard é correlata à dificuldade em isolar a variável dependente das variáveis independentes e "estranhas" durante o teste. Segue comentando que supera a margem estatística de erro a resposta de muitos pacientes diante do mesmo procedimento. Além disso, os psicoterapeutas não são escolhidos aleatoriamente e o psicoterapeuta é um fator decisivo em uma cura pela via psicoterapêutica. E, 


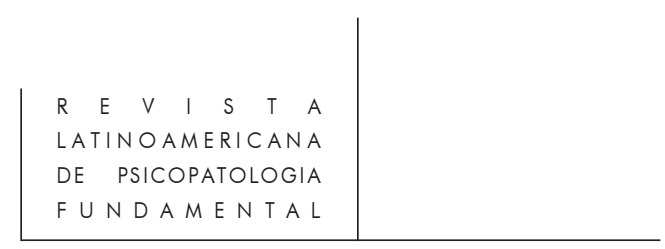

apontando o quanto é espinhosa esta ambição empírica, Howard comenta que a perda de dados é inevitável e que é "impossível que possamos padronizar um tratamento que seja feito no mesmo caminho, pelo mesmo psicoterapeuta, sobre diferentes pacientes". Parsons (1996) também comenta que há limitações não negligenciáveis nos testes controlados. Estas limitações residem na possibilidade das técnicas estatísticas não registrarem a participação da seleção dos pacientes que se submetem aos testes. Sledge (1994) aponta que há uma diferença significativa quando as psicoterapias são avaliadas em circunstâncias experimentais e quando são avaliadas no "mundo real" em que o tratamento é oferecido em "condições naturais". Uma discrepância de números raramente encontrada em outros ramos da ciência experimental. Deveria levantar alguma suspeita sobre as medidas criteriosamente colhidas e bradadas com eficiente retórica por aqueles que vêem evidências decisivas nestes números.

Além do mais, está sendo pago um alto preço para o enquadre de uma atividade tão complexa, que se constrói passo a passo, e que não exibe uma linearidade formal ao mecanicismo apropriado ao ambiente experimental. Glass (1984), a este respeito, diz: "a interpretação da relação entre o processo empregado e o resultados das psicoterapias é complicado pelo fato do resultado poder influenciar o processo. Aspectos das psicoterapias usualmente registrados como variáveis independentes que influenciam o resultado (por exemplo, a atmosfera do tratamento e as ações específicas do paciente e do terapeuta) podem também ser afetados pelo resultado emergente do tratamento, isto é, estas variáveis podem ser conseqüência do processo, mais que causas". Assim, é necessário que o método de avaliação das psicoterapias possa incluir esta temporalidade diacrônica, irreversível, ao lado da constatação de que as causas e as conseqüências do fenômeno em estudo substituem-se reciprocamente, como é próprio em fenômenos nos quais a história está incluída em sua definição.

Prigogine (1996) já levantou esta questão, que denominou "o paradoxo do tempo", ao sacar o hiato entre o caráter "temporalmente reversível" da lei de Newton, da equação de Schrödinger e o vetor tempo presente como fato subjetivo e histórico irredutível. Diz o químico laureado pelo Nobel:

A questão do tempo - do que ele cria, preserva ou destrói - esteve sempre no centro do pensamento humano, mas, até finais do século XIX, nenhum esquema conceitual havia estabelecido a equivalência entre uma planta que cresce, floresce e morre e uma planta que revive, se torna jovem outra vez e retorna às suas sementes. Não obstante, esta negação radical do tempo era postulada implicitamente pelas idéias clássicas sobre as leis da natureza, e reiterada na maioria dos livros recentes de físicos de destaque, como Feynman ou Hawking. É sugerido que a irreversibilidade pode resultar de nossos enfoques, do ponto de vista de "pouco detalhe" que impomos 


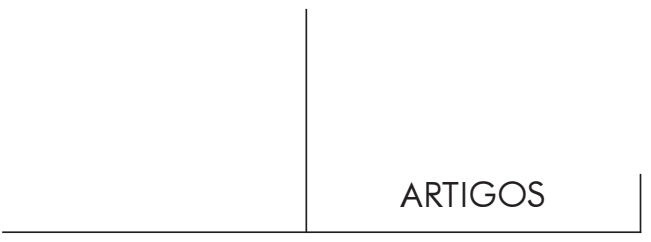

ao estudar um universo de tempo reversível descrito pelas leis clássicas da natureza. Essa atitude pode ser em parte ideológica: deriva da busca de certeza. Poderia haver também uma razão técnica. Como incorporar a irreversibilidade nas leis fundamentais da natureza sem incorrer em algumas contradições?

Para Prigogine, o importante nesta questão é que da inclusão do elemento "tempo" "nasce a transição entre a "velha" e a "nova" ciência". Neste escrito, no entanto, o argumento do químico serve para marcar a diferença radical entre um campo, o das ciências naturais, que pode trabalhar racionalmente com a noção de reversibilidade temporal e dá-se razoavelmente bem com o tipo de objetividade proposto pela metodologia empírica, em confronto com um campo, o psiquismo humano, patológico ou não, em que a noção de reversibilidade temporal choca-se com a menor chama de racionalidade. A pergunta a ser feita é: esta distinção entre reais, com e sem tempo reversível, não obrigaria a um outro método que implicaria uma outra suposição de objetividade? É interessante notar que o pesquisador, quando se defronta com o fato humano, é humano também e pode perfeitamente ser palco do sofrimento que se propõe a medir. $\mathrm{O}$ que coloca à crença na objetividade um verdadeiro problema.

O terceiro pilar depreende-se de uma certa tendência presente na literatura sobre a função das psicoterapias que pode ser nomeado "o paradoxo da exigência". A razão deste nome é que as psicoterapias, quando sob teste empírico, são chamadas a exibir um desempenho que não é de forma alguma exigido a outros procedimentos terapêuticos mais ao gosto do modelo médico. Uma intenção que pressupõe uma certa absolutização das psicoterapias. Isto é, se são eficientes, que demonstrem este poder para além de qualquer dúvida. Se as psicoterapias, mesmo úteis, são mais custosas, então, que respondam pelo todo. Esta é uma outra circunstância na qual, independentemente dos estilos, as psicoterapias recebem a mesma severidade dos críticos.

Uma das situações nas quais isto se evidencia é quando os empiristas, acostumados a um interessante darwinismo ideológico, acreditam que uma teoria se estabelece e domina na medida em que suas proposições expliquem melhor os fatos de uma dada realidade. O detalhe de que este "dado" é, freqüentemente, histórico e culturalmente localizado não quer dizer nada a estes estupendos darwinistas. Assim é postulado - não demonstrado - que a multiplicação de estilos, de teorias, de procedimentos explicativos em um determinado ramo do saber denunciaria a condição pré-científica. Deste modo, o campo psicoterapêutico estaria irremediavelmente dentro desta condição. Apenas no campo psicanalítico é possível reconhecer orientações distintas. Há os freudianos, os kleinianos, os lacanianos, os analistas do ego, apesar dos psicanalistas orientarem-se em torno de uma concepção comum de que a palavra é o meio eficiente de cura e que não há ser sem referência a 


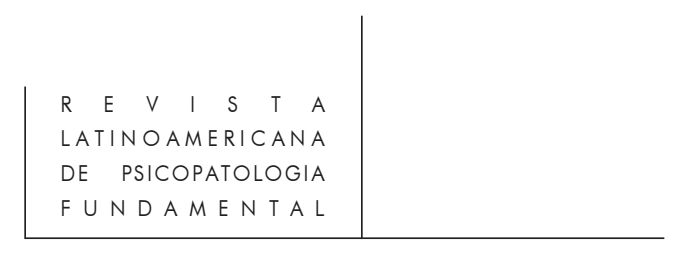

um outro. Fora do campo psicanalítico e aparentados com a psicanálise, estão outros estilos que também julgam a investigação e a expressão elementos importantes do tratamento. A psicoterapia existencial, a psicologia analítica, o psicodrama estão entre eles. Além destes, podem ser listadas as técnicas de extração cognitivacomportamental que não colocam o acento na investigação e na expressão e apostam em um protocolo orientador baseado na autonomia do fenômeno patológico diante da subjetividade do paciente. Este cenário, no qual vários estilos estão presentes, está sob suspeita. A multiplicação de esquemas explicativos seria um indicativo de pouca eficiência, tendo em vista que nenhum domina e mostra nítida superioridade sobre o outro.

No entanto, em outras áreas da terapêutica médica, apesar de existir uma situação semelhante - os meios terapêuticos são múltiplos -, a acusação de pouca ciência e ineficiência não é aventada com tanta veemência. Isto ocorre com os antibióticos (Ramadam, 1992) e com os antidepressivos e não há comentários de teor semelhante. Pelo contrário, a multiplicação destes fármacos é comumente interpretada como uma evidência cristalina da dedicação e do esforço dos médicos, dos pesquisadores, dos centros científicos, dos laboratórios farmacêuticos com a saúde da humanidade e não sinal de ineficiência e acientificidade. Assim, as bactérias podem ser Gram+ ou Gram- e receberem antibióticos diferentes e a depressão pode ser tratada com antidepressivos serotoninérgicos ou noradrenérgicos que a ciência está assegurada. No entanto, se o sujeito, diante do aparelho psicoterapêutico, tiver suas dificuldades com a simbolização e a responsabilidade pessoal e "responder" melhor diante da disciplina própria às terapias cognitivo-comportamentais e não adequar-se às condições de analisabilidade e, portanto, não "responder" ao tratamento psicanalítico, é uma prova cabal de que a psicoterapia e a ciência caminham em mãos opostas.

Esta lógica de dois pesos duas medidas é também presente em situações clínicas ordinárias. Caso a suspensão de um tratamento medicamentoso seja seguida de uma recaída do paciente, a razão de ressurgimento do quadro clínico comprova o quanto o fármaco é fundamental para a estabilização da patologia e a correção exógena do desequilíbrio dos neurotransmissores é uma teoria acertada. Se a recaída se dá após a interrupção da psicoterapia, não é incomum que a conclusão penda para a demonstração de ineficiência da psicoterapia. Esta é uma maneira de lembrar que, claramente, apesar de todos os esforços, a objetividade científica apresenta mais senões do que a pressa gostaria de discutir.

Dentro deste olhar sobre a ciência, é interessante perceber que tal não ocorre apenas no campo em discussão. Hetherington (1984), discutindo a objetividade destas mensurações, afirma que alguns erros de medida são relativos a pressões internas e externas ao dispositivo científico que trabalham no sentido de exigir resultados, além da expectativa do pesquisador em ver suas hipóteses confirmadas. Se isto se 


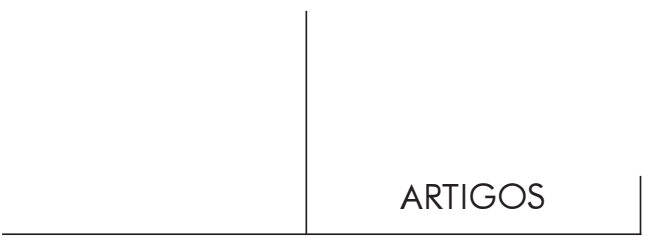

dá com a precisa astrofísica, ramo da ciência natural comentado por Hetherington, o que dizer deste simulacro de ciência natural que está sendo aplicado às psicoterapias? Esta permanece uma questão aberta. Se, por um lado, não se justifica leviandades com os resultados - pois estão sendo levados em conta, também não se justifica acreditar no que ditam as pesquisas de maneira decisiva.

Convém não recalcar que as condições que Hetherington levanta como influentes nas medidas, estão maciçamente presentes no campo psicoterapêutico, um campo já mais vulnerável à influência do sujeito. Pois, à revelia do interesse dos próprios psicoterapeutas em aferir a validade de sua prática, a partir do final da década de 1970, uma nova peça entrou no jogo. Em 1979, o Subcomitê de Saúde do senado norte-americano, liderado por Jay Constantine, decretou que “... gostaria de ver provas melhores sobre a utilidade das várias psicoterapias, antes de expandir o reembolso para tais atividades pelo Medicare" (Marshall, 1980). Segundo o mesmo projeto, as psicoterapias deveriam mostrar-se seguras e genuinamente eficazes em melhorar a saúde mental dos pacientes. Isto caracteriza uma pressão externa ao trabalho propriamente científico e obrigou a uma verdadeira corrida pela demonstração de eficiência. Pela via mais rápida: o verificacionismo empirista. Hine (1982) imediatamente pôs em relevo os enganos presentes na proposição do Subcomitê de Saúde, ao dizer que o furor demonstrativo de eficiência baseava-se em uma concepção equivocada de ciência. Em coro a este escrito, Hine não concorda com a imitação que psicólogos e cientistas sociais fazem do método, da linguagem e do modelo das ciências naturais.

Enfim, não há por parte deste escrito a intenção de sugerir que a ciência não seja o melhor meio de aferir a validade e a confiabilidade das terapêuticas médicas. Simplesmente, alerta para a chance do campo psicoterapêutico ter sido, ou estar sendo, avaliado por critérios que não são os mais adequados. Esta inadequação pode incluir desde a conformação melhor do dispositivo cognitivo-comportamental que o psicanalítico ao aparelho empírico até a aceitação preferencial de projetos de pesquisa mais de acordo com os objetos passivos da natureza - como se não fossem "falsos objetos empíricos" - aos quais a reversibilidade temporal é racionalmente aplicada. Além, obviamente, de uma circunstância propriamente ideológica, produto do espírito do tempo e na crença generalizada no cientificismo, que favorece as leituras bioquímicas, genéticas e neuronais sobre a história do sujeito e a subjetividade. No primeiro caso, além do pouco apetite dos psicanalistas pelo banquete empírico, a psicanálise estaria sendo subavaliada. No segundo caso, as psicoterapias estariam sendo prejudicadas igualmente. No terceiro caso, o espírito canônico que marca a psicanálise é mais prejudicado que o espírito pragmático e solucionador de problemas das psicoterapias cognitivo-comportamentais.

Mas é necessário reconhecer a vocação onipotente da metodologia experimental que julga qualquer tarefa possível, mesmo quando fatores indecidíveis, próprios às 


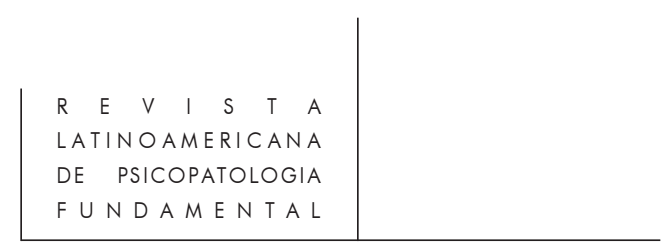

estruturas complexas, participam da cena estudada. A negação deste tópico tem obscurecido a capacidade crítica dos setores envolvidos nesta tarefa de formalização da atividade psicoterapêutica. E esta tarefa é levada adiante - e isto é certo como resposta da comunidade psicoterapêutica a uma admoestação, se bem que justificável, por instâncias, nossos interlocutores imaginários, mais preocupadas com o número do que com o processo e a ética.

\section{Epílogo}

O ponto fundamental, por enquanto, é salientar que as pesquisas que avaliam a eficiência das psicoterapias, sem dúvida, produzem resultados, não obstante a via produtora destes resultados apresentar mais máculas do que o desejável. Há sim uma influência externa, de natureza econômica, declarada que determina a pressa na produção dos resultados. Além disso, os testes são efetivados como se os senões à sua aplicação fossem banalidades ligeiras e a proclama de suas conclusões é feita sem considerar esta particularidade. Há uma máscara de seriedade que tem organizado protocolos e certezas cada vez mais freqüentes na literatura psiquiátrica e leiga. Poucos são os autores que levantam preocupações sobre o caráter objetivo e impessoal das experiências que sustentam a verificabilidade das proposições em teste. E põe em xeque o recurso à experiência como critério ou cânone da validade do conhecimento, traço característico do empirismo, que, no tocante a este tema, apresenta mais furos do que se pode esperar de metodologia tão rigorosa. Portanto, a empiricidade do objeto, que consiste na comparação e no exame dos resultados por qualquer um que possua os meios adequados, não se estabelece claramente.

Obviamente, o texto aqui apresentado alinha-se entre os textos críticos. No entanto, este trabalho foi escrito com o objetivo de participar da discussão e do processo mundialmente em curso. Não se trata de um libelo denuncista da ingenuidade empirista. Não faltam críticas à ingenuidade ou à onipotência empirista na literatura filosófica sobre a ciência. Oliva (1990) adverte que

... o critério verificacionista de cientificidade consegue se justificar mais como uma denúncia dirigida a discursos depreciáveis como ideológicos do que como adequada reconstrução identificadora do tipo de significatividade que deve ser exibido pelos enunciados que pretendem fazer parte dos textos científicos (...), pois (...) o verificacionismo tem pendularmente abraçado formulações ou bem demasiado liberais a ponto de não conseguir vetar qualquer enunciado, ou bem demasiado restritivo a ponto de barrar importantes formas expressivas utilizadas pela própria linguagem científica. E quando não é bem demasiado complacente nem draconiano, é de difícil aplicação...

Assim, o aparelho empírico tem lá seus problemas que apenas a adesão ideológica - que o método deveria contentar-se em denunciar - permite que ele seja 


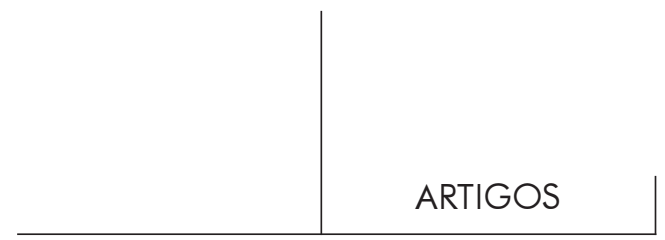

tido e havido como superior. Agora, esta posição não vem em socorro da atitude do psicanalista que ao assumir "uma aparente superioridade e auto-suficiência (...) defende a primazia da intuição e a impossibilidade de qualquer julgamento objetivo sobre sua clínica..." (Lowenkron, 2000). Pois este é o perfeito ingênuo, na medida em que acredita que a intuição seja apropriada a qualquer coisa. E, convém frisar, que mesmo este discurso, calcado na mesma literatura médica que consagrou a via medicamentosa e psicoterapêutica pragmática, que é também calcado na literatura filosófica prudente sobre os critérios de cientificidade não cai nos ouvidos de quem tem tomado as decisões no campo econômico e publicitário das terapêuticas. E é com estes que dialogamos, os interlocutores imaginários. Assim, seria interessante que os psicanalistas retomassem o timão de sua nave e criativamente, aproveitando as falhas do empirismo, participassem de forma mais ativa na cena atual.

O discurso psicanalítico deve ser respeitado enquanto influencia, recebe influências, debate e é debatido por qualquer das disciplinas que a ele fazem fronteira. E, se o campo psicanalítico, epistemologicamente, justifica-se como um campo independente da medicina, isto não ocorre, por mais incoerente e injusto que pareça, no campo dos serviços de saúde. E não há como espernear contra este estado de coisas.

Assim, é necessária a aproximação a este esquema empírico. A impressão deixada pela leitura dos textos psicanalíticos - como antes foi dito - paradoxalmente faz crer que os psicanalistas acreditam na independência do objeto empírico. E, barrados por esta crença, dizem que "o que se passa numa análise não se presta ao empirismo". E o psicanalista que assim se posiciona está coberto de razão. A psicanálise não se presta ao empirismo. O detalhe é que as correntes psicoterapêuticas que concorrem com a psicanálise, pelo exposto anteriormente, também não. A psicoterapia é um laboratório que trabalha com fenômenos complexos, no sentido de E. Morin (1975, 1983, 1994), em que se multiplicam interações, retroações e uma série de elementos indecidíveis. É possível formular que a clínica - e não somente a psicanalítica - é, em muitos sentidos, oposta à concepção positivista de ciência. Esta concepção supõe, ao lado da unicidade do método, que "a definição dos objetos tem de ser clara, unívoca, inconfundível e não pode dar margem a erro de interpretação" (Pereira, 2000) para responder à exigência do cânone experimental. Não haveria como justamente o psicanalista, constituído por concepções teóricas consistentes e sólida experiência clínica, desenvolver procedimentos que se conformem à complexidade, sem submissão à unicidade do método? De resto, como visto, unidade metodológica que não é unanimemente exigida pelos epistemólogos. Mas sem pouco caso aos nossos interlocutores imaginários. Estes, nesses tempos que rolam, têm o poder de desmontar a transferência que a cultura tem com a psi- 


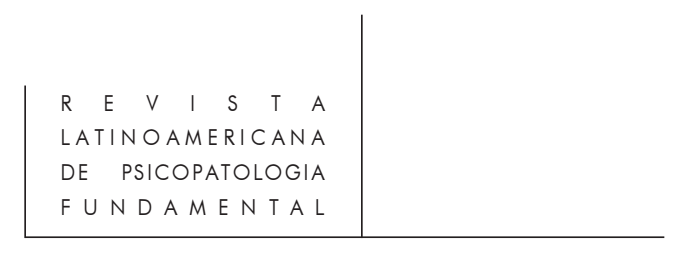

canálise. Neste sentido, é interessante observar psicanalistas - Wallerstein (1996), Kächele (1997), Fonseca (1997) - debruçados sobre como operacionalizar a pesquisa empírica em psicanálise, sem a devida crítica ao empirismo. Se, por um lado, respondem aos interlocutores imaginários, por outro, parecem imbuídos da concepção de que o objeto empírico é uma realidade a ser conhecida e não uma invenção levada a cabo pelo sujeito. O objeto empírico, não custa repetir, não é mais que um recorte e quem recorta é o sujeito.

A questão apresenta nitidamente dois pólos. Não há mais lugar ao psicanalista que julga um valor a impossibilidade de transmitir o que se passa no ato analítico como se este fosse - e isto é falso! - palco de uma intimidade tão inefável que não há que prestar contas. E a psicanálise também não ganha muito se assume o dispositivo experimental sem a devida crítica à reificação do objeto de pesquisa. Uma ilusão que - paradoxalmente - paralisa a apresentação de resultados aos interlocutores imaginários. O dilema atual não é muito distinto do impasse do homem que nos ensinou que não há objeto que não se construa sem a participação do sujeito e, em outro momento, acreditou que estava desenvolvendo um método que teria o melhor dos destinos empíricos. Diz Freud (1905): “... mas estou seguro de que todo aquele que empreenda com igual método a investigação de tais fenômenos acabará por compartilhar minha posição...” Trata-se de um Freud crítico ao objetivismo simples dos empiristas e esperançoso desta mesma simplicidade.

Não é preciso mais fazer o mesmo. O objeto empírico é uma construção e não está dado na natureza. Invente-se o da psicanálise e que se fale dele.

Se o psicanalista escuta, ele sabe falar.

\section{Referências Bibliográficas}

Argan, G.C. Arte moderna. São Paulo: Editora Schwarcz, 1996.

BINSWANGER, L. Sobre psicoterapia (possibilidad e facticidad de la acción psicoterapêutica. Artículos e conferencias escogidas. Madrid: Gredos, 1973.

Chalmers, A. A fabricação da ciência. São Paulo: Ed. Unesp, 1994.

Clare, A. Psychiatry in Dissent. Controversial Issues in Thought and Practice. Londres: Routledge, 1989.

Clarkin, J.F.; Pilkonis, P.A.; Magruder, K.M. Psychotherapy of depression. Implications for reform health care. Arch. Gen. Psychiatry, 53, p. 717-723, 1996.

FonseCA, V.R.J.M.M. Considerações sobre a pesquisa psicanalítica. Jornal de Psicanálise, 30, p. 39-46 1997.

Fourez, G. (1995) A construção das ciências. Introdução à filosofia e à ética das ciências. São Paulo: Ed Unesp, 1995.

FRANKFORD, D. Scientism and economism in the regulation of health care. J. Health Polit. Policy Law, 19, p. 773-799, 1994. 


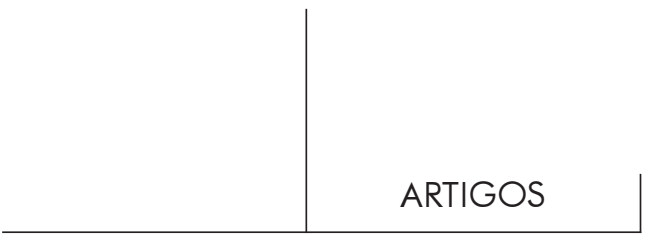

Freud, S. (1895). Proyecto de una psicologia para neurologos. Obras completas, Madrid: Biblioteca Nueva, 1973. v. I. Sobre psicoterapia. Op. cit. v. I. (1905.) Analisis fragmentario de una histeria. Op. cit. v. I.

Glass, R.M. Psychotherapy: scientific art or artistic science? Arch. Gen. Psychiatry., 41, p. 525-526, 1984.

Granger, G.-G. A ciência e as ciências. São Paulo: Ed. Unesp, 1994.

Hanns, L.A. Psicoterapias sob suspeita - A psicanálise no século XXI. Trabalho apresentado nas "Noites Brasileiras" da SBPSP, 2000. (Inédito).

Hetherington, N.S. Just how objective is science? Nature 5945, p. 727-730, 1984.

Hine, F.R.; Weiman, D.J.; Simpson, D.M. Effectiveness of psychotherapy: problems of research complex phenomena. Am. J. Psychiatry, 139, p. 204-208, 1982.

Hollon, S.D.; Du Rubeis, R.J.; Evans, M.D. Cognitive therapy and pharmachotherapy for depression: singly or in combination. Arch. Gen. Psychiatry, 49, p. 774-81, 1992. (Citado por Schestatsky \& Fleck.)

HowARD, K.I.; OrLInsky, D.E.; LUEGER, L.R. Clinically relevant outcome research in individual psychotherapy. New models guide the researcher and clinician. Br. J. Psychiatry, 165, p. 4-8, 1994.

KäChele, H. Pesquisa do processo psicanalítico: da pesquisa clínica à pesquisa científica básica. Jornal de Psicanálise, 30, p. 75-93, 1997.

LowENKRON, T.S. Questão da pesquisa em psicanálise: "prova-se do pudim comendo-o?” Trabalho apresentado na Reunião Científica da SBPRJ, 2000. (Inédito.)

Margison, F.; Shapiro, D. Psychological treatments for depression. Br. J. Psychiatry. 168, 127 [letter], 1996.

Markowitz, J.C. Psychotherapy on dysthymia. Am. J. Psychiatry, 151, p. 11141121, 1994.

Marshall, E. Psychotherapy faces tests of worth. Science, 4426, p. 35-36, 1980.

MEYER, A.E. Problems of process-efficiency studies in psychotherapy. Acta Psychiatr Belg. 91, p. 117-134, 1996.

Morin, E. O enigma do homem. Para uma nova antropologia. Rio de Janeiro: Zahar, 1975.

O problema epistemológico da complexidade. Publicações Europa-América. Mem Martins, 1983.

A epistemologia da complexidade. In Schnitman, D.F. (org.). Novos paradigmas, cultura e subjetividade. Porto Alegre: Artes Médicas, 1994.

Oliva, A. Verificacionismo: critério de cientificidade ou crítica à ideologia? In OLIVA, A. (org.). Epistemologia e cientificidade em questão. Campinas: Papirus, 1990.

OMER, L.; London, P. Signal and noise in psychotherapy. The role and the control of non-specific factors. Br. J. Psycchiatry, 155, p. 239-245, 1989.

PARloff, M.B. Placebo control in psychotherapy research: a sine qua non or a pla- 
cebo for research problems? J. Consult. Clin. Psychol, 54, p. 79-87, 1985.

Parsons, J.B.; Thase, M.E.; Crits-Cristoph, P. The role of psychotherapy in the treatment of depression. Review of two practice guidelines. Arch. Gen. Psychiatry, 53, p. 283-290, 1996.

Pereira, M.E.C. Comentário às conferências de abertura do Simpósio "As medidas do Inconsciente", da Escola Brasileira de Psicanálise-SP, 2000.

Pignarre, P. $O$ que é o medicamento? Um objeto estranho entre ciência, mercado e sociedade. São Paulo: Editora 34, 1999.

Prigogine, I. O fim da ciência? In Schnitman, D.F. (org.). Novos paradigmas, cultura e subjetividade. Porto Alegre: Artes Médicas, 1996.

Ramadam, Z.B.A.Psicoterapia e bases terapêuticas da medicina. Temas. Teoria e prática do Psiquiatra, 44, p. 116-133, 1992.

Russel, R.L.; Orlinsky, D.E. Psychotherapy research in historical perspective. Implications for mental health care policy. Arch. Gen. Psychiatry, 53, p. 708715, 1996.

Schestatsky, S.; Fleck, M. Psicoterapia das depressões. Rev. Bras. Psiquiatr. (suplemento:depressões) Si41-Si47, 1999.

SLEDGE, W.H. Psychotherapy in US: challenges and opportunities. Am. J. Psychiatry, 151, p. 1.267-1.270, 1994.

Tillet, R. Psychotherapy assesment and treatment selection. Br. J. Psychiatry, 168, p. 10-15, 1996.

Weissman, M.M.; Akiskal, H.S. The role of psychotherapy in cronic depression: a proposal. Compr. Psychiatry, 25, p. 23-31, 1984.

Woody, G.E.; Mc Lellan, A.T.; Luborsky, L.; O’Brien, C.P.; Beck, A.T.; Blaine, J.; Hirman, I.; Hole, A. Psychotherapy for opiate addicts: does it help? Arch. Gen. Psychiatry, 40, p. 639-645, 1983.

Woody, G.E.; Mc Lellan, A.T.; Luborsky, L.; O’Brien, C.P. Psychotherapy in community methadon program. Avaliation study. Am. J. Psychiatry, 152, p. 1.302-1.308, 1995.

W ALLERSTEIN, R.S. Psychoanalytic research: where do we disagree? The Newsletter of the IPA, 5, p. 15-17, 1996.

\section{Resumos}

El autor discute las posíbles implicaciones para el ejercício de la Psicoanalisis el contexto que obliga que la eficiencia de los procedimientos terapêuticos sea determinada por el método empírico. Alerta que la facilidad esta metodología, partiendo de otras posiciones filosóficas y éticas, no debe servir como argumiento para la comunidad psicoanalítica hacer de ombros las críticas que surjan.

Palabras llave: Psicoterapía, empirismo, pesquisa 


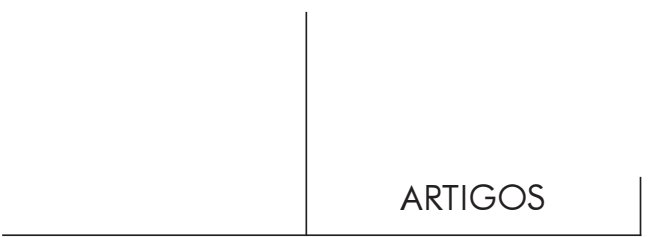

L'auteur discute les possibles implications pour l'exercise de la psychanalyse, le contexte qu'obligue que l'efficience des procédures thérapeutiques soit raffiné pour le méthode empirique. Alerte que la facilité de se critiquer cet méthodologie, à partir d'autres positions philosophiques et éthiques, ne doit pas servir comme argument pour la communauté psychanalytique recevoir avec dédain les critiques qu'arrivent.

Mots clés: Psychotherapie, empirism, recherche

The author discuss the implications to the psychoanalityc practice the context which compel the effectiveness of the therapeutic matters be find out by empiric issues. Watch that the facility to criticize these methodological issues, by others philosofical and ethical speeches, isn't an argument for the psychoanalitical community take with disdain critical issues.

Key words: Psychotherapy, empiricism, research

Versão inicial recebida em julho de 2000.

Versão revisada recebida em novembro de 2000. 